\title{
The Development of CAM200 - Low Power Hall Thruster
}

\author{
By Dan LEV, ${ }^{1)}$ Raanan EYTAN, ${ }^{1)}$ Gal ALON,${ }^{1)}$ Abraham WARSHAVSKY, ${ }^{1)}$ Leonid APPEL, ${ }^{1)}$ Alexander KAPULKIN ${ }^{2)}$ \\ and Maxim RUBANOVYCH ${ }^{2)}$ \\ 1) Rafael - Advanced Defense Systems Ltd., Haifa, Israel \\ ${ }^{2)}$ Asher Space Research Institute (ASRI), Technion - Israel Institute of Technology, Haifa, Israel
}

(Received July 24th, 2015)

\begin{abstract}
The present work describes key activities in the development campaign of the CAM200 low power Hall thruster from initial prototype testing to concurrent full performance mapping. The development program presented included proof-of-concept tests, experimental and numerical validation of physical mechanisms, wall material selection, performance testing, thruster engineering model structural, thermal and magnetic simulations followed by an engineering model production as well as full performance mapping. During the development campaign CAM200 demonstrated exceptional performance with anode specific impulse and anode efficiencies above $1500 \mathrm{sec}$ and $43 \%$, respectively, at a power level of $250 \mathrm{~W}$. Future activities include thruster-cathode coupling test, full thruster unit lifetime qualification and full electric propulsion system coupling test, all part of the MEPS project, a joint European-Israeli endeavor.
\end{abstract}

Key Words: Electric Propulsion, Hall Thruster, Low Power, CAM200

\section{Nomenclature}

$$
\begin{array}{ll}
\text { Isp } & : \text { specific impulse } \\
\dot{m} & : \text { mass flow rate } \\
P & : \text { electrical power } \\
T & : \text { thrust } \\
V & : \text { voltage } \\
\eta & : \text { efficiency }
\end{array}
$$

Subscripts

$$
\begin{aligned}
& a \text { : anode } \\
& \text { c : cathode } \\
& d \text { : discharge } \\
& m \text { : magnets }
\end{aligned}
$$

\section{Introduction}

Due to their small size micro-satellites $(10-100 \mathrm{~kg})$ are power limited and conventionally utilize chemical propulsion for their manuevering requirements. However, the use of high efficiency low power $(<300 \mathrm{~W})$ electric propulsion with Hall Effect Thrusters (HET) can enhance micro-satellites' capabilities and allow them to perform a veriety of missions, particularly in Low Earth Orbits (LEO). In addition, thanks to the associated high specific impulse the use of low power HETs allows for propellant mass reduction, thus reducing the overall satellite mass. This, in turn, enables the enlargement of the mission payload if needed. Although HET technology carries these advantages at power levels of $50 \mathrm{~W}$ to $300 \mathrm{~W}$ HETs suffer from low efficiency and short operating lifetime relative to their higher power cousins. ${ }^{1,2)}$

The Co-axial Anode Magneto-Isolated Longitudinal Anode (CAMILA) HET confronts low power Hall thruster weaknesses. This is done by a combination of an unconventional design and a unique magnetic field topology. The CAMILA HET incorporates co-axial anodes, contrary to conventional HET design where the gas distributer is also the anode. The co-axial anode structure assists in forming equipotential lines parallel to the thruster walls; therefore repelling incoming ions and increasing propellant efficiency relative to conventional Hall thrusters. ${ }^{3,4)}$ In addition, a specific class of the CAMILA thruster, denoted Full-CAMILA, contains two internal magnetic coils that generate magnetic field lines parallel to the anode surface to focus the ions at the center of the thruster cavity. ${ }^{5,6)}$

The CAMILA Hall thruster was developed at the Asher Space Research Institute (ASRI) at the Technion in cooperation with Rafael $^{7)}$ and initially tested at the Soreq NRC facility. After preliminary proof-of-concept set of tests on the CAMILA thruster prototype development continued at Rafael with the purpose of improving some engineering aspects of the thruster and designing a flight-ready model.

This paper presents the CAM200 development campaign, from prototype research to Engineering Model (EM) experimentation.

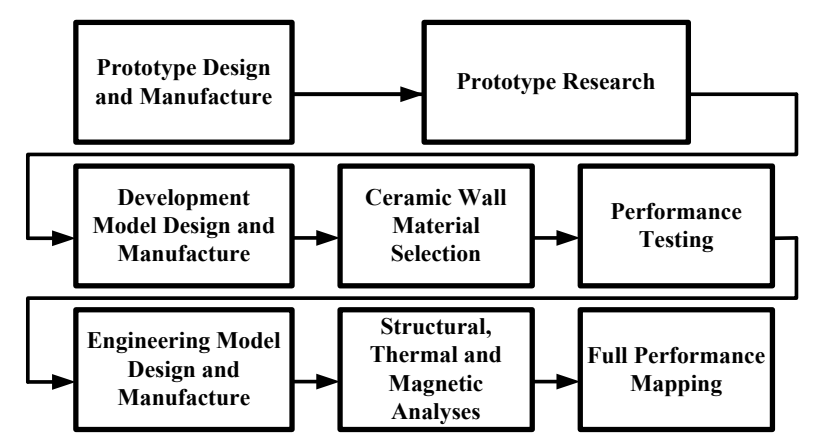

Fig. 1. Development flow chart of the CAM200 thruster. 


\section{CAM200 Development Campaign}

Key activities in CAM200 development program are presented in Fig. 1. The development program commenced with the design, manufacture and experimental investigation of the CAMILA prototype and currently is in the midst of a full thruster performance mapping. An elaborated description of each of the development keysteps is presented hereafter.

\section{Prototype Research}

\subsection{Prototype experimentation}

Laboratory prototype of the CAMILA Hall thruster (Fig. 2) was designed, manufactured and experimentally tested. ${ }^{4,7,8)}$ During the initial proof-of-concept experimental investigation two configurations of the CAMILA thruster were explored the Full-CAMILA and the Simplified-CAMILA. Each thruster configuration consists of co-axial anodes yet the magnetic topology is different as described above. All configurations of the CAMILA thruster were designed to operate in the $100 \mathrm{~W}$ to $300 \mathrm{~W}$ power range.

During the initial experimental campaign the Full-CAMILA Hall thruster demonstrated exceptional performance with anode efficiencies higher than 0.5 and anode specific impulse values higher than $1500 \mathrm{sec}$ at power levels lower than $250 \mathrm{~W}$. These performance values are the highest ever recorded for very low power Hall thrusters. Simplified-CAMILA thruster performance was found slightly lower as described in the subsequent chapters.

Additionally, Langmuir probe measurements of the plasma properties inside the thruster were conducted to shed light on the CAMILA thruster's high performance ${ }^{9,10)}$. The measurements confirmed high ion density in the channel center. These results, along with numerical simulations (referred to hereafter) of the ion flow field, strengthen the postulation that the CAMILA Hall thruster configuration gives rise to efficient propellant ionization via low ion-to-wall loses.

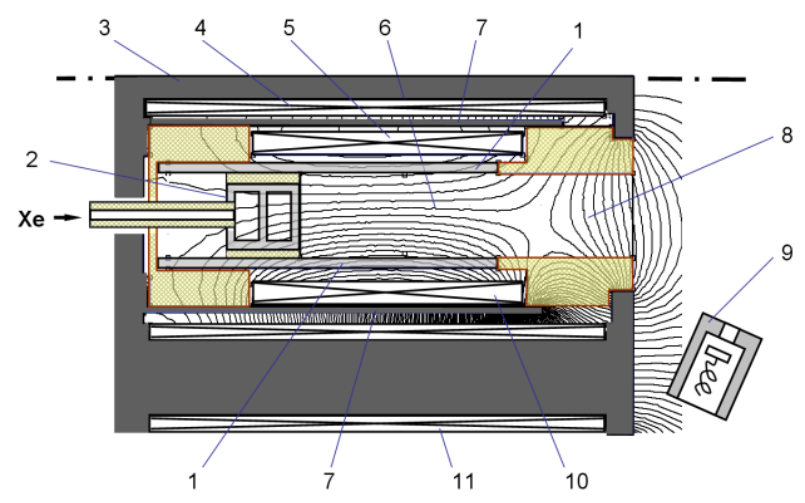

Fig. 2. Schematic of the CAMILA Hall thruster prototype. ${ }^{7)}$

1 - Anode; 2 - Gas distributor; 3 - Magnetic circuit; 4 - Central magnetic coil; 5 - Inner anode coil; 6 - Anode cavity; 7 - Magnetic screens; 8 Acceleration channel; 9 - Cathode-neutralizer; 10 - Outer anode magnetic coils; 11 - Outer magnetic coils.

\subsection{Numerical simulations}

Particle in Cell (PIC) simulations of the CAMILA thruster and its derivatives were conducted to better understand the physical mechanisms behind the CAMILA Hall thruster performance. Early numerical work $^{5,6,10)}$ focused on the plasma inside the thruster cavity and simulated both the ionization and acceleration regions of the thruster. The results obtained from the simulation confirmed the sources for high CAMILA thruster performance and were in accordance with the experimental measurements.

Recent numerical work $^{11,12)}$ focuses on the plasma properties in the thruster plume outside the thruster cavity. The simulated results show plume electron temperature in the order of $1 \mathrm{eV}$ with exponentially decreasing number density which are expected in typical HET plume plasmas. Nevertheless, experimental verification of the simulated results are yet to be published.

\section{Ceramic Wall Material Selection}

After initial validation further Simplified-CAMILA thruster development was conducted at Rafael with the continuous support of ASRI. ${ }^{13)}$ Although Simplified-CAMILA exhibited lower performance, relative to Full-CAMILA, it was chosen thanks to its simpler magnetic circuit design. Subsequently a Development Model (DM), also denoted CAM200-DM, was designed, manufactured and tested. CAM200-DM incorporated engineering improvements compared with the CAMILA prototype thruster. For example, improved ceramic insulation, the use of additive layer manufacturing (3-D printing) for the reduction of cost and manufacture duration as well as the development of production processes.

An experimental program was conducted to identify the most suitable ceramic wall material for CAM200-DM that can satisfy both structural integrity requirements and exhibits highest performance, both in terms of thrust efficiency and low erosion. ${ }^{14)}$ To do so three material candidates were examined: (1) High Purity BN (HP-BN) (2) M26-BN and (3) Zirconia-based $\mathrm{BN}$ (ZSBN). All materials and their key properties are presented in Table 1.

Table 1. Key properties of the three BN-based materials examined in the CAM200 material selection test plan.

\begin{tabular}{|c|c|c|c|c|c|c|}
\hline Property & \multicolumn{2}{|c|}{$\begin{array}{c}\text { HP-BN } \\
\text { (High } \\
\text { Purity) }\end{array}$} & \multicolumn{2}{|c|}{ M26-BN } & \multicolumn{2}{|c|}{ ZSBN } \\
\hline Crystalline Phase & \multicolumn{2}{|c|}{ Hex BN } & \multicolumn{2}{|c|}{$\begin{array}{l}\mathrm{BN}-60 \%, \\
\mathrm{SiO}_{2}-40 \%\end{array}$} & \multicolumn{2}{|c|}{$\begin{array}{l}\mathrm{BN}-45 \% \\
\mathrm{Zr}_{2} \mathrm{O}_{3}-45 \%\end{array}$} \\
\hline Directionality & & $\perp$ & & $\perp$ & & $\perp$ \\
\hline $\begin{array}{l}\text { Flexural Strength } \\
\text { [MPa] }\end{array}$ & 59 & 45 & 62 & 34 & 144 & 107 \\
\hline $\begin{array}{l}\text { Thermal Conductivity } \\
\left(\text { at } 25^{\circ} \mathrm{C}\right)[\mathrm{W} / \mathrm{mK}]\end{array}$ & 27 & 29 & 11 & 29 & 24 & 34 \\
\hline $\begin{array}{l}\text { Dielectric Strength } \\
{[\mathrm{kV} / \mathrm{mm}]}\end{array}$ & \multicolumn{2}{|c|}{$>10$} & \multicolumn{2}{|c|}{66} & \multicolumn{2}{|c|}{$>9$} \\
\hline
\end{tabular}

Three sets of ceramic wall rings, identical in geometry yet made of different materials, were manufactured. For each set of rings the following experiments were conducted: (1) Shock 
and Vibration test, (2) HET performance test and (3) Relative erosion test after 80 hours of operation.

The exhaustive wall material selection program resulted in the selection of boron nitride grade M26, also referred to as 'Borosil', as the most suitable wall material for the CAM200 thruster.

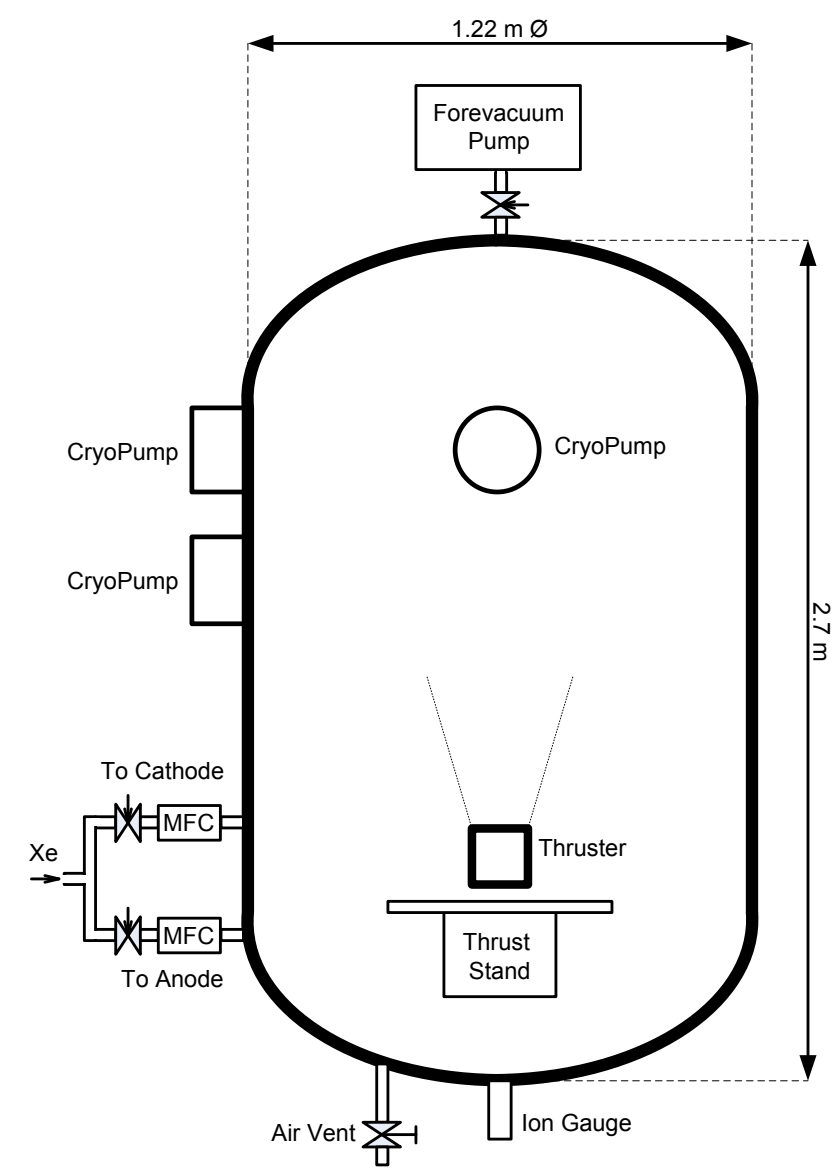

Fig. 3. Schematic of the Asher Space Research Institute (ASRI) electric propulsion laboratory experimental facility (not to scale).

\section{Performance Testing}

To verify that the CAM200-DM thruster shares the same high performance characteristics as the prototype CAMILA thruster an experiment was executed to measure the thruster performance.

\subsection{Test facility}

Performance tests were conducted at the Asher Space Research Institute (ASRI) electric propulsion laboratory at the Technion (Fig. 3). The test facility includes a $1.22 \mathrm{~m} \varnothing \times 2.7 \mathrm{~m}$ stainless steel vacuum chamber with inner volume of approximately $3.2 \mathrm{~m}^{3}$. The chamber is equipped with a 'RUTA WAU 501/D65B/A' forevacuum pump with pumping speed of 230 liter/s of air. Three 'Sumitomo' CP-22 cryopumps are located on the vacuum chamber's opposite end from the thruster. The combined measured pumping speed achieved is approximately 9,000 liter/s on xenon. The residual pressure of the vacuum chamber is lower than $9 \times 10^{-8}$ Torr. During thruster operation at a total flow rate of $1.2 \mathrm{mg} / \mathrm{s}$ of xenon, chamber pressure was lower than $2 \times 10^{-5}$ Torr (Xenon corrected). It should be noted that this chamber pressure value is expected to affect thruster performance due to residual vacuum cahmber gas ingested by the thruster. Suitable calculation of the effect on thruster performance can be found at the end of chapter 5 .

Pressure is measured using an 'Ionivac' sensor, model ITR90 from 'Leybold', located behind the thruster. The 'Ionivac' pressure gauge is calibrated by the manufacturer and has a declared precision of $15 \%$. A commercial flow controller, capable of measuring flow rate from 0 to 1.96 $\mathrm{mg} / \mathrm{s}$, model M100b from MKS, controls xenon flow to the thruster's gas distributor. Similarly, a flow controller controls flow rate to the cathode, from 0 to $0.98 \mathrm{mg} / \mathrm{s}$, and was set to $0.15 \mathrm{mg} / \mathrm{s}$ during all tests. The mass flow controllers are calibrated by the manufacturer, with a declared precession of $1 \%$ of full scale. The thrust stand used is a feedback-controlled inverted pendulum type, manufactured for ASRI by PLATAR LTD, Moscow, Russia. It is capable of thrust measurements from 1 to $200 \mathrm{mN}$. Measurement accuracies, as declared and verified by the manufacturer, are $\pm 3.5 \%$ between 5 to $10 \mathrm{mN}$ and $\pm 3 \%$ between 10 to $20 \mathrm{mN}$. During tests the thrust stand is calibrated using weights once in every two hours.

The experiments were conducted on CAM200-DM, using a low-current heaterless hollow cathode procured from Kharkiv Aviation Institute (KhAI) of Kharkiv, Ukraine. A dedicated Ignition Block (I/B) supplies the high voltage pulse necessary to ignite the cathode as well as the keeper holding voltage required to sustain emitter-keeper plasma after cathode discharge is set. The thruster discharge voltage is supplied by the main $\mathrm{P} / \mathrm{S}$ that connects between the anode and cathode. Two power supplies feed current to the magnetic circuit; one to the outer coils assembly and the other to the centeral coil. This arrangement enables small magnetic field topology adjustments during tests in case unexpected thruster behavior is encountered.

\subsection{Operation test plan}

The performance test plan commenced with 4 hours of thruster operation to remove all gas impurities absorbed in the ceramics prior to vacuum chamber pumpdown. Performance investigation was conducted at six power levels according to Table 2.

Table 2. Operational points of CAM200-DM during performance testing.

\begin{tabular}{|c|c|c|c|c|c|}
\hline$\#$ & $\begin{array}{c}\mathbf{P}_{\mathbf{d}} \\
{[\text { Watt }]}\end{array}$ & $\begin{array}{c}\mathbf{V}_{\mathbf{d}} \\
{[\text { Volt }]}\end{array}$ & $\begin{array}{c}\dot{\mathbf{m}}_{\mathbf{a}} \\
{[\mathrm{mg} / \mathrm{s}]}\end{array}$ & $\begin{array}{c}\dot{\mathbf{m}}_{\mathbf{c}} \\
{[\mathrm{mg} / \mathrm{s}]}\end{array}$ & $\begin{array}{c}\mathbf{P}_{\mathbf{m}} \\
{[\text { Watt }]}\end{array}$ \\
\hline $\mathbf{1}$ & 100 & 200 & 0.60 & 0.15 & 13 \\
\hline $\mathbf{2}$ & 130 & 250 & 0.60 & 0.15 & 13 \\
\hline $\mathbf{3}$ & 177 & 275 & 0.70 & 0.15 & 22 \\
\hline $\mathbf{4}$ & 207 & 275 & 0.78 & 0.15 & 22 \\
\hline $\mathbf{5}$ & 254 & 275 & 0.93 & 0.15 & 22 \\
\hline $\mathbf{6}$ & 304 & 275 & 1.09 & 0.15 & 22 \\
\hline
\end{tabular}




\subsection{Test results and discussion}

The performance of CAM200-EM, in terms of thrust, specific impulse and anode efficiency, assembled with the chosen M26-BN discharge rings are presented in Fig. 4(a)-(c). It can be deduced from the figures that CAM200-DM exhibits the same high performance as the CAMILA prototype. CAM200-DM, at power level of $100 \mathrm{~W}$, generates thrust higher than $5 \mathrm{mN}$ and anode efficiency higher than $20 \%$. Additionally, at higher power levels of about $300 \mathrm{~W}$ CAM200-DM generates thrust higher than $16 \mathrm{mN}$, specific impulse around $1600 \mathrm{sec}$ and anode efficiency of about $45 \%$.
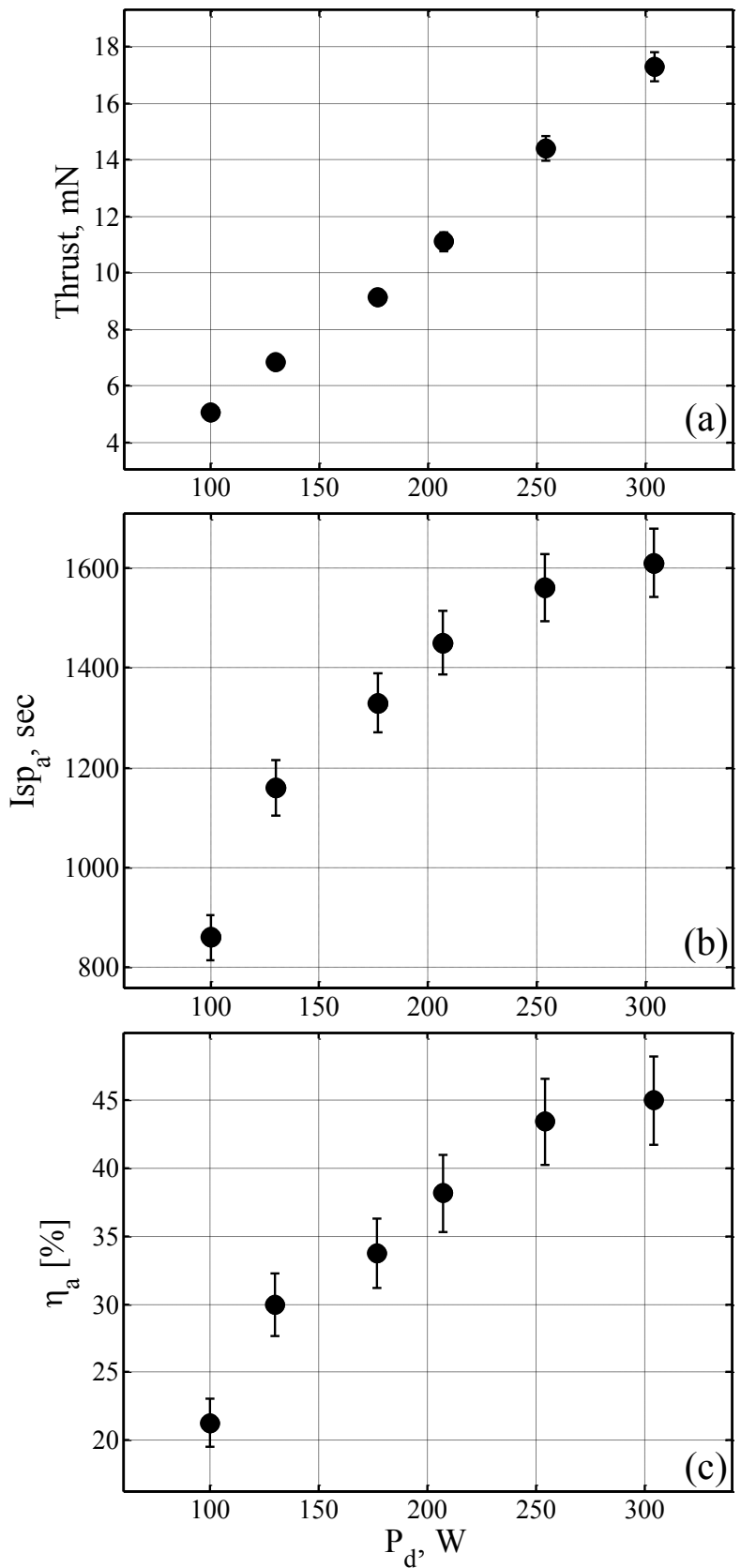

Fig. 4. Measured (a) thrust, (b) Specific impulse and (c) anode efficiency of CAM200-DM. Estimated correction for the effect of the ambient gas ingested is given in section 5.4. The power invested in generating the magnetic field is $13 \mathrm{~W}$ and $22 \mathrm{~W}$ for anode power under and above $150 \mathrm{~W}$ respectively.
All performance results are satisfactory and clearly indicate on the advantage of using the CAM200 Hall thruster at low power under $300 \mathrm{~W}$.

Lastly, the power invested in the magnets is given in Table 2. This additional power requirement is expected to reduce the overall thruster efficiency, especially at low power levels. However, the thruster is still under development and there is an ongoing activity aimed at identifying and qualifying the most suitable coil material, wire gauge, number of turns and conducted current while maintaining the exact same magnetic field topology in the thruster. This activity will reduce the power to the magnets while keeping thruster operation the same as presented in Fig. 4.

\subsection{Ambient pressure effect on performance}

The vacuum chamber pressure is such that some ambient gas enters the thruster during operation and participates in the ionization and acceleration processes. The ingested gas is expected to raise thruster performance. To estimate the impact of ambient gas ingestion we use the known 'Ingestion Model', also shown in Eq. (1), ${ }^{15)}$

$$
\dot{\mathrm{m}}_{\mathrm{ing}}=\frac{\left(\mathrm{m}_{\mathrm{Xe}}^{1 / 2} \mathrm{~A}_{\mathrm{ch}} \mathrm{P}_{\mathrm{am}}\right)}{\left(2 \pi \mathrm{k}_{\mathrm{B}} \mathrm{T}_{\mathrm{am}}\right)^{1 / 2}}
$$

where $\dot{\mathrm{m}}_{\text {ing }}$ is the ingested ambient mass flow rate, $\mathrm{m}_{\mathrm{Xe}}$ is the mass of one ambient gas atom, here taken to be the mass of xenon atom $\left(2.2 \times 10^{-25} \mathrm{~kg}\right), \mathrm{A}_{\mathrm{ch}}$ is the thruster channel exit area $\left(2,073 \mathrm{~mm}^{2}\right.$ for CAM200), $\mathrm{P}_{\mathrm{am}}$ is the vacuum chamber ambient pressure, $\mathrm{K}_{\mathrm{B}}$ is the Boltzmann constant $\left(1.38 \times 10^{-23}\right.$ $\mathrm{J} / \mathrm{K})$ and $\mathrm{T}_{\mathrm{am}}$ is the ambient gas temperature, here assumed to be $300 \mathrm{~K}$.

Using Eq. (1) it is found that the estimated ingested mass flow rate to thruster input mass flow rate ratio is about $1.8 \%$ for all operational points. Since the measured thrust, $\mathrm{T}$, is proportional to the overall mass flow rate that enters the thruster, the measured thrust is over-estimated by the same fraction of $1.8 \%$. In a similar fashion, anode specific impulse $\left(\operatorname{Isp}_{\mathrm{a}} \propto \mathrm{T} / \dot{\mathrm{m}}_{\mathrm{a}}\right)$ and anode efficiency $\left(\eta_{\mathrm{a}} \propto \mathrm{T} \cdot \mathrm{Isp}_{\mathrm{a}} / \dot{\mathrm{m}}_{\mathrm{a}}\right)$ are over-estimated by $1.8 \%$ and $3.6 \%$ respectively.

\section{Structural, Thermal and Magnetic Analyses}

After the basic structure and materials of the CAM200 thruster were determined an Engineering Model (EM) of the thruster, denoted CAM200-EM, was designed and manufactured (Fig. 5). In CAM200-EM additional engineering improvements were implemented in order for the thruster to properly withstand structural, magnetic and thermal environmental conditions under the European Cooperation for Space Standardization (ECSS). 


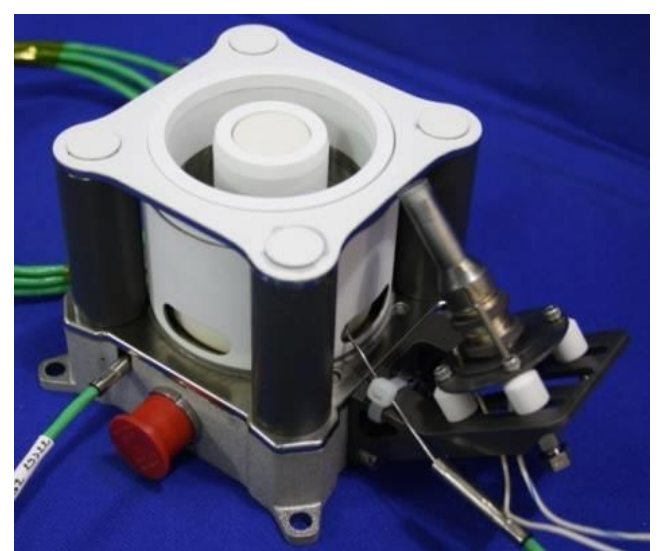

Fig. 5. Picture of CAM200-EM Hall thruster. The cathode is a commercially available cathode.

As a result various finite element simulations were implemented to estimate the structural, magnetic and thermal behavior of the thruster under the expected mission environmental conditions. Examples of the CAD and simulation models are presented in Fig. 6.

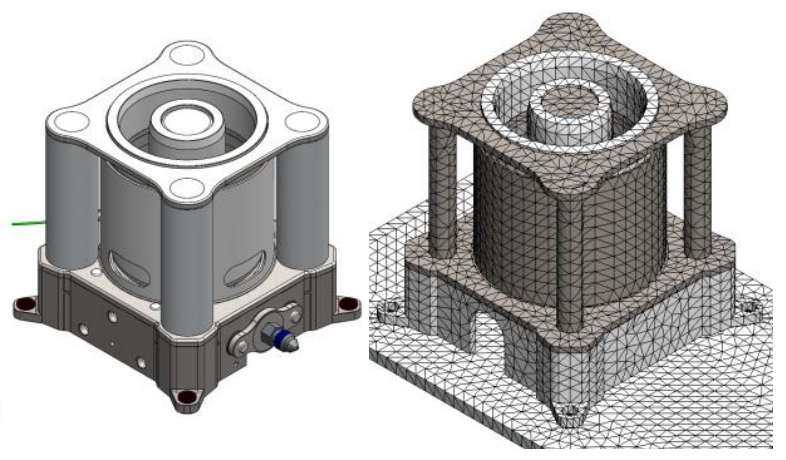

Fig. 6. CAD model and simulation model of the CAM200-EM Hall thruster

\subsection{Structural analysis}

Structural simulation results indicated structural integrity throughout the expected structural environmental conditions which are similar to the conditions of the Ven $\mu$ s mission qualification process. ${ }^{16)}$ Dedicated shock and vibration tests were conducted to reduce fracture risk in regions susceptible to structural constraints and to validate the EM design. All tests were successful thus validating the integrity of the computer-modeled CAM200-EM thruster. ${ }^{17,18)}$

At the same time it is important to note that these structural analysis and tests were conducted on the engineering model of the CAM200 thruster. The main purpose of the presented structural analysis is to validate thruster body materials, manufacturing techniques and interfaces between the thruster parts. After final thruster design is completed Qualification Model (QM) of the thruster will be produced and structural validation process repeated. This process shall include both updated structural analyses and another round of shock and vibration tests.

\subsection{Thermal analysis}

Thermal simulations were performed at three thruster operational points - $100 \mathrm{~W}$ and exposed to open space, $200 \mathrm{~W}$ nominal operation and $250 \mathrm{~W}$ facing the sun. The power loads to the different parts of the thruster were computed using a Hall thruster heat load model that takes into consideration the thruster's operational conditions, basic thruster structure, measured electron temperatures at various regions of the thruster and cathode power deposition. ${ }^{19)}$

The computed heat dissipated through conduction, radition and ion beam, as well as the maximum temperature formed on the thruster body, are presented in Table 3.

Table 3. Computed power dissipated via conduction to the thruster bracket ( $\left.\mathrm{P}_{\text {cond }}\right)$, radiation to space $\left(\mathrm{P}_{\mathrm{rad}}\right)$ and power invested into the ion beam $\left(\mathrm{P}_{\text {beam }}\right)$. The rightmost column contains the maximum material temperature predicted on the thruster body.

\begin{tabular}{|c|c|c|c|c|c|}
\hline$\#$ & $\begin{array}{c}\mathbf{P}_{\mathbf{d}} \\
{[\text { Watt] }}\end{array}$ & $\begin{array}{c}\mathbf{P}_{\text {cond }} \\
\text { [Watt] }\end{array}$ & $\begin{array}{c}\mathbf{P}_{\text {rad }} \\
\text { [Watt] }\end{array}$ & $\begin{array}{c}\mathbf{P}_{\text {beam }} \\
{[\text { Watt }]}\end{array}$ & $\begin{array}{c}\mathbf{T}_{\mathbf{m a x}} \\
{\left[{ }^{\circ} \mathrm{C}\right]}\end{array}$ \\
\hline $\mathbf{1}$ & 100 & 3.2 & 49 & 47.8 & 388 \\
\hline $\mathbf{2}$ & 200 & 4 & 70 & 126 & 435 \\
\hline $\mathbf{3}$ & 250 & 4 & 74 & 172 & 448 \\
\hline
\end{tabular}

The results from the hottest expected thruster scenario under operation at $250 \mathrm{~W}$ are presented in Fig. 7. It can be observed from the thermal analysis results that even at the most extreme case of highest power operation while facing the sun the highest thruster temperature is lower than $450^{\circ} \mathrm{C}$. This is an acceptable temperature for the inner ceramic channel that can withstand much higher temperatures.

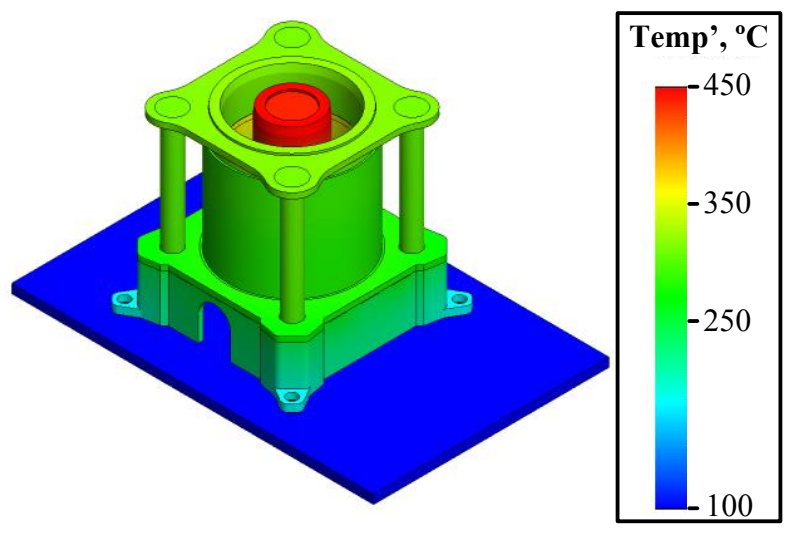

Fig. 7. Thermal simulation results for the $250 \mathrm{~W}$ anode power case while thruster is facing the sun.

Similarly to the structural analysis the aim of the thermal analysis in the engineering model phase is to validate thruster materials and basic thermal design. The thermal analysis shall be repeated on the qualification model of the thruster and validated using laboratory measurements at different locations along the thruster body and ceramic channel.

\subsection{Magnetic analysis}

CAM200-EM magnetic topology was simulated using a commercial off-the-shelf software and is presented in Fig. 8. It 
can be observed that the thruster carries a conventional HET magnetic topology with a concave-convex shape near the thruster exit plane.

Since CAM200 incorporates conventional magnetic field topology the expected low ion wall loss may originate only from the electric field directionality due to the co-axial anode configuration. This comes in contrast with magnetically shielded Hall thrusters where the measaured low ion loss is a consequence of the unique magnetic field topology of the thruster. ${ }^{20)}$ Nevertheless, it is still unknown, at this point, whether the expected low ion loss in CAM200 would lead to high thruster life expectancy. The latter is still to be determined as part of a thruster lifetime test.

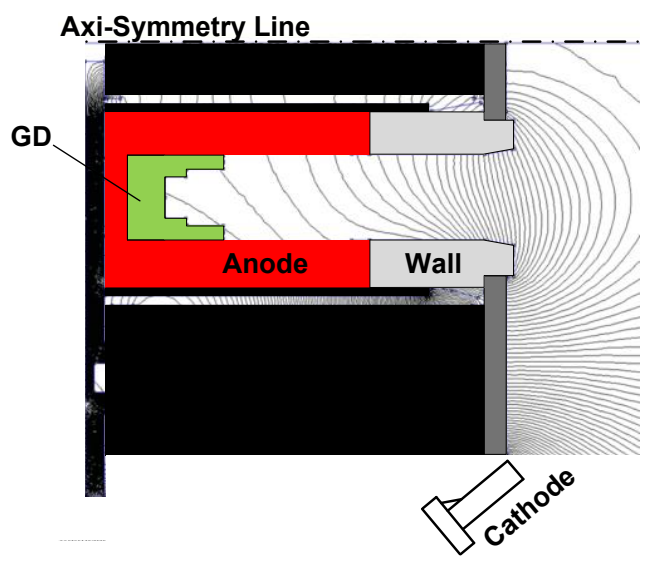

Fig. 8. CAM200-EM magnetic field topology.

\section{Full Performance Mapping}

The current state of the on-going CAM200-EM development program includes full performance mapping. In this development phase thruster performance is investigated at a wide range of operational parameters beyond the parameter range specified in the MEPS project specification requirements $(100 \mathrm{~W}-250 \mathrm{~W})$. The main purpose of the performance mapping is to identify low power shutdown limits, detremental temperatures at high power levels and electrical insulation endurance at high discharge voltages.

Additionally, the thruster mapping effort includes performance sensitivity to changes in magnetic field magnitude. This check will aid in determining the required operational point, in terms of magnetic field magnitude, that will maintain thruster operation stability throughout mission lifetime. Also, this check will allow the reduction of magnetic field power to the minimum needed to properly operate the thruster; therefore increasing system efficiency.

\section{Conclusion}

CAM200 Hall thruster development has been overviewed from initial prototype design to current thruster performance mapping.

The development program presented included proof-of-concept tests, experimental and theoretical validation of physical mechanisms, wall material selection, performance and instabilities testing, thruster EM production and simulations as well as performance mapping. This meticulous thruster development plan ensures a reliable and robust thruster.

Further CAM200 development will be conducted as part of the MEPS project ${ }^{21,22)}$ and will include: thruster-cathode coupling experiment, full characterization test, shock and vibration tests, lifetime test and a full system coupling test. The end goal of the program is to fully qualify the CAM200 thruster and present it as a viable solution for various types of space missions.

\section{References}

1) Ahedo, E. and Gallardo, J. M.: Scaling Down Hall Thrusters, Proceedings of the 29th International Electric Propulsion Conference (IEPC), Mar. 2003, Toulouse, France.

2) Manzella, D., Oleson, S., Sankovic, J., Haag, T., Semenkin, A. and Kim, V.: Evaluation of Low Power Hall Thruster Propulsion, Proceedings of the 32nd Joint Propulsion Conference (JPC), Jul. 1996, Lake Buena Vista, FL, USA.

3) Kapulkin, A. and Guelman, M.: Theoretical Modeling of Ionization Processes in Anode Cavity of CAMILA Hall Thruster, Proceedings of the 31st International Electric Propulsion Conference (IEPC), Sep. 2009, Ann Arbor, MI, USA.

4) Rubanovych, M., Balabanov, V., Kapulkin, A. and Behar, E.: Experimental Investigations of Component Determining CAMILA Hall Thruster Performance, Proceedings of the $33^{\text {nd }}$ International Electric Propulsion Conference (IEPC), Oct. 2013, Washington DC, USA.

5) Kronhaus, I.: Experimental and Numerical Investigations of the Physical Processes in a Co-Axial Magneto-Isolated Longitudinal Anode Hall Thruster, Ph.D. Thesis, Aerospace Dept., Technion Israel Institute of Technology, 2012.

6) Kronhaus, I., Kapulkin, A., Guelman, M. and Natan, B. Investigation of Two Discharge Configurations in the CAMILA Hall Thruster by the Particle-in-Cell method, Plasma Sources Sci. Technol., 21 (2012), pp. 035005.

7) Guelman, M., Kapulkin, A., Balabanov, V., Rabinovich, L. and Appelbaum, G.: A New Low-Power Hall Thruster Concept, Proceedings of the The 59th International Astronautical Congress, Oct. 2008, Glasgow, Scotland.

8) Kapulkin, A., Balabanov, V., Rubanovich, M., Behar, E., Rabinovich, L. and Warshavsky, A.: CAMILA Hall Thruster: New Results, Proceedings of the 32nd International Electric Propulsion Conference (IEPC), Oct. 2011, Wiesbaden, Germany.

9) Kronhaus, I., Kapulkin, A., Balabanov, V., Rubanovich, M., Guelman, M. and Natan, B.: Investigation of Physical Processes in CAMILA Hall Thruster using Electrical Probes, J. Phys. D: Appl. Phys. 45 (2012), pp. 175203

10) Kronhaus, I., Kapulkin, A., Balabanov, V., Rubanovich, M., Guelman, M. and Natan, B.: Discharge Characterization of the Coaxial Magnetoisolated Longitudinal Anode Hall Thruster, Journal of Propulsion and Power, 29 (2013), pp. 938-49.

11) Laterza, M. and Guelman, M.: Numerical Modeling of Plume Divergence in a CAMILA Hall Thruster Cluster, Proceedings of the 55th Israel Annual Conference on Aerospace Sciences, Feb. 2015, Tel-Aviv, Israel.

12) Laterza, M. and Guelman, M.: Plume Modeling of a Two CAMILA Hall Thruster Cluster for Thrust Vectoring, Proceedings of the 34th International Electric Propulsion Conference (IEPC), Jul. 2015, Hyogo-Kobe, Japan.

13) Herscovitz, J., Zuckerman, Z. and Lev, D.: Electric Propulsion Developments at Rafael, Proceedings of the 34th International Electric Propulsion Conference (IEPC), Jul. 2015, Hyogo-Kobe, Japan.

14) Eytan, R., Lev, D., Alon, G., Warshavsky, A., Kapulkin, A. and 
Rubanovych, M.: Wall Material Selection Process for CAM200 Low Power Hall Thruster, Proceedings of the 34th International Electric Propulsion Conference (IEPC), Jul. 2015, Hyogo-Kobe, Japan.

15) Randolph, T., Kim, V., Kozubsky, K., Zhurin, V. and Day, M.: Facility Effects on Stationary Plasma Thruster Testing, Proceedings of the 23rd International Electric Propulsion Conference (IEPC), 1993, Seattle, WA, USA.

16) Warshavsky, A., Rabinovich, L., Reiner, D., Herscovitz, J. and Appelbaum, G.: Qualification and Integration of the Venus Electrical Propulsion System. Proceedings of the European Space Propulsion Conference (SP), May 2010, San Sebastian, Spain.

17) Misuri, T., Ducci, C., Andrenucci, M., Waldvogel, B., Lev, D., Alon, G. and Dannenmayer, K.: MEPS Engineering Model Development and Test, Proceedings of the 5th Space Propulsion Conference (SP), May, 2016, Rome, Italy.

18) Lev, D., Katz Franco, D., Eytan, R. and Appel, L.: Performance Characterization and Vibration Test of the CAM200 Low Power Hall Thruster, Proceedings of the 52nd Joint Propulsion Conference (JPC), Jul. 2016, Salt Lake City, UT, USA.

19) Lev, D.: CAM200-EM - Power Load Model. Internal Report, RAF\#12177236-v1: Rafael - Advanced Defense Systems
Ltd., 2015.

20) Mikellides, I. G., Katz, I., Hofer, R. R., Goebel, D. M., De Grys, K. H. and Mathers, A.: Magnetic Shielding of the Acceleration Channel in a Long-Life Hall Thruster, Phys. Plasmas, 18 (2011), pp. 033501.

21) Misuri, T., Albertoni, R., Ducci, C., Waldvogel, B., Appel, L., Eytan, R., Lev, D., Dannemayer, K. and Di Cara, D.: MEPS: A Low Power Electric Propulsion System for Small Satellites, Proceedings of the 10th IAA Symposium on Small Satellites for Earth Observation, Apr. 2015, Berlin, Germany.

22) Misuri, T., Andrenucci, M., Herscovitz, J., Waldvogel, B. and Dannenmayer, K.: MEPS Programme - New Horizons for Low Power Electric Propulsion Systems, Proceedings of the 34th International Electric Propulsion Conference (IEPC), Jul. 2015, Hyogo-Kobe, Japan. 